Int. J. Dev. Biol. 61: 367-374 (2017)

doi: $10.1387 / \mathrm{ijdb} .160352 \mathrm{ss}$

\title{
Regulation of body size in Caenorhabditis elegans: effects of environmental factors and the nervous system
}

\author{
TAKASHI NAGASHIMA ${ }^{1}$, SHOICHI ISHIURA ${ }^{2}$ and SATOSHI SUO*,3 \\ ${ }^{1}$ Department of Biological Sciences, Graduate School of Science, The University of Tokyo, Tokyo, \\ ${ }^{2}$ Department of Medical Life Systems, Faculty of Life and Medical Sciences, Doshisha University, Kyoto and \\ ${ }^{3}$ Department of Pharmacology, Faculty of Medicine, Saitama Medical University, Saitama, Japan
}

\begin{abstract}
Body size is one of the basic traits of animals and is regulated to adapt to the environment. Animals perceive environmental stimuli with sensory neurons, and signals from the nervous system alter the size of organs, thus regulating body size. The model animal Caenorhabditis elegans is particularly suited for genetic analysis of body size regulation, and has already contributed to the elucidation of various genetic pathways that regulate body size. In this review, we summarize the available literature regarding environmental factors that regulate body size and the role of the nervous system in such regulation. We discuss in detail a recent report on body size regulation by the neurotransmitter, dopamine.
\end{abstract}

KEY WORDS: body size, environmental factors, dopamine, Caenorhabditis elegans

\section{Environmental factors control animal body size}

Body size is one of the most important features of an organism. Several environmental factors are known to affect animal body size, and food is one of the most influential ones. Food-rich conditions promote cell division and allow animals such as Drosophila to grow larger (de Moed et al., 1997). Size differences could also arise due to the quality of food. Intake of high-fat diets during early life results in obesity in mice (Lin et al., 2000). High-fat diets could also epigenetically regulate the metabolism via modification of adiponectin and leptin genes (Masuyama and Hiramatsu, 2012). Apart from nutritional factors, an association between body size and ambient temperature has also been reported. Tail length and surface area of the ear of mice have been positively correlated with ambient temperature (Serrat et al., 2008). Lower temperatures can cause animals to grow larger. For example, lower temperatures have been reported to increase the body size of female Drosophila by increasing the cell size; in males, not only the cell size, but the cell number also increases, indicating that the mechanism of body size regulation differs between females and males (French et al., 1998; de Moed et al., 1997; Robertson, 1959). In addition, Drosophila also responds to changes in humidity; surface area of the wings was found to be larger in low-humidity conditions (Kennington et al., 2003). Although several such environmental factors affect the body size, the mechanism behind this regulation is not fully understood. The nematode Caenorhabditis elegans is particularly suited for the study of body size regulation because it exhibits rapid development and is amenable to extensive genetic analyses. Various signaling pathways that regulate body size have been identified through studies using $C$. elegans.

\section{TGF- $\beta$ pathway regulates body size}

Transforming growth factor- $\beta$ (TGF- $\beta$ ) signaling regulates the animal body size (Patterson and Padgett, 2000; Tuck, 2014). TGF- $\beta$ superfamily ligands are important in the regulation of cell identity, function, and survival, and play important roles in many diseases (Massagué, 2012; Wu and Hill, 2009). TGF- $\beta$ ligands are secreted by various cell types, and activate TGF- $\beta$ receptors, which are heterodimers of types 1 and 2 receptor subunits. The TGF- $\beta$ receptors activate SMAD (Sma- and Mad-related) proteins, which enter the nucleus upon activation and function as transcription factors to induce the expression of various genes (Fig. 1).

The TGF- $\beta$ ligand, DBL-1, has been identified in $C$. elegans (Morita et al., 1999; Suzuki et al., 1999). DBL-1 is homologous to Drosophila Decapentaplegic (Dpp) and mammalian bone morphogenetic proteins. $d b$-1-deficient mutants are smaller than the wild-type animals. DBL-1 does not affect cell division; instead, it

Abbreviations used in this paper: MAP kinase, mitogen-activated protein kinase; SMAD, Sma- and Mad-related; TGF- $\beta$, transforming growth factor- $\beta$; TOR, target of rapamycin.

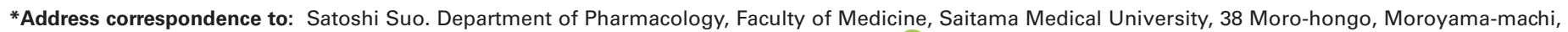
Iruma-gun, Saitama 350-0495, Japan. Tel: +81-49-276-1157. E-mail: ssuo@ saitama-med.ac.jp iD http://orcid.org/0000-0002-4469-0301
} 
regulates body size by stimulating the growth of hypodermal cells, which surround the animal body. In mammals, changes in cell size and number could result in variations in body size. However, the number of cells in large and small $C$. elegans mutants has been found to be unchanged in all analyses performed so far. This is presumably because of the small number of cells and the rigid cell lineage (Morita et al., 2002). DAF-4 and SMA-6 form a complex that functions as the DBL-1 receptor, which activates the SMAD transcription factors, SMA-2, SMA-3, and SMA-4 (Estevez et al., 1993; Krishna et al., 1999). SMA-3 interacts with LIN-31, a winged helix transcription factor (Wang et al., 2005). RNAi knockdown of lin-31 results in slightly reduced body size (Rual et al., 2004). LIN31 is also involved in the TGF- $\beta$ signaling for tail development in male C. elegans (Baird and Ellazar, 1999). In addition, the SMADinteracting transcription cofactor SMA-9, which is homologous to the Drosophila Schnurri (Shn), functions as a downstream factor

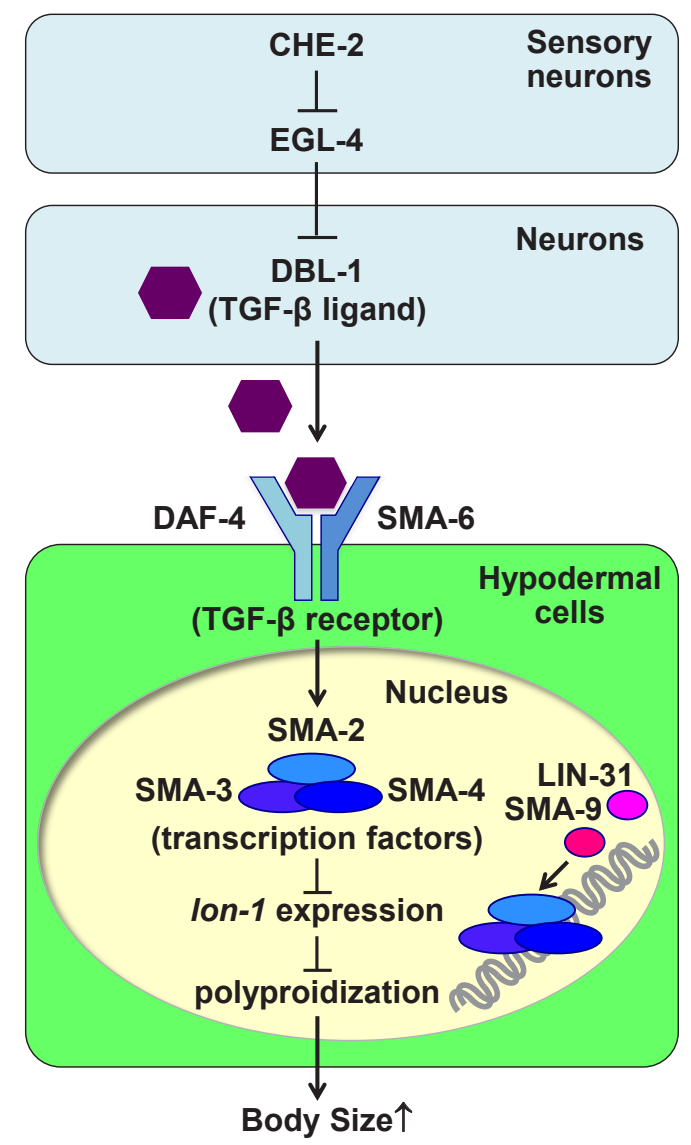

Fig. 1. Transforming growth factor- $\beta$ (TGF- $\beta$ ) pathway regulates body size of Caenorhabditis elegans. CHE-2, which is required for sensory functions, and the cGMP-dependent protein kinase, EGL-4, act upstream of the TGF- $\beta$ ligand, DBL-1. CHE-2 suppresses EGL-4 in sensory neurons, and EGL-4 negatively regulates DBL-1. DBL-1 transmits the signal from neurons to the hypodermis. Several SMAD transcription factors, SMA-2, SMA-3, and SMA-4, act downstream of the TGF- $\beta$ receptors, SMA-6 and $D A F-4$, expressed in the hypodermal cells. LIN-31 works as a transcription factor and interacts with SMA-3. SMA-9, a transcription cofactor, also acts downstream of $D B L-1$. The TGF- $\beta$ signaling negatively regulates the expression of lon-1. LON-1 affects polyploidization in hypodermal cells, which in turn regulates body size. of DBL-1 in body size regulation (Liang et al., 2003).

DBL- 1 is expressed in the neurons, whereas the receptor SMA-6 and the SMADs function in the hypodermal cells to regulate body size (Yoshida et al., 2001). Therefore, it has been proposed that DBL-1, secreted from neurons, transmits the signals to the hypodermal cells, thus regulating body size. LON-1 is homologous to the cysteine-rich secretory protein family and acts downstream of the TGF- $\beta$ pathway in body size regulation. Expression of Ion-1 is suppressed by DBL-1 via the SMAD proteins (Maduzia et al., 2002; Morita et al., 2002). LON-1 regulates the polyploidization of hypodermal cells, which in turn regulates hypodermal cell size, thereby affecting body size.

\section{Other genetic factors}

Insulin/IGF-1 signaling is involved in many metabolic and neural regulations in animals, including energy metabolism, development, longevity (Dyer et al., 2016; Nässel et al., 2015), as well as body size. In mammals, the insulin/IGF signal acts downstream of the growth hormone $(\mathrm{GH})$ to regulate body size (Blutke et al., 2014; Lundberg et al., 2015). Insulin/IGF also regulates body size in invertebrates, which do not possess $\mathrm{GH}$. Drosophila with mutations in the insulin/IGF-1 signaling pathway (chico and dinr) are smaller than wild-type animals. The insulin/IGF-1 signal has been reported to regulate the body size in a cell-autonomous manner (Böhni et al., 1999; Brogiolo et al., 2001). In addition to the insulin-like peptides, the steroid molting hormone (ecdysone) and the sesquiterpenoid juvenile hormone are involved in body size regulation in Drosophila (Truman and Riddiford, 2007). These two hormones regulate growth and body size through signals related to the nutritional condition (Layalle et al., 2008; Shiao et al., 2008; Shimada-Niwa and Niwa, 2014). In C. elegans, forty insulin-like peptides have been identified. Each peptide is differentially expressed in different organs, including many neurons, and their expression levels change under different environmental conditions or during the different developmental stages (Ritter et al., 2013). Despite these different insulin-like peptides, $C$. elegans has only a single receptor, DAF-2. As with mammals, phosphoinositide 3-kinase (PI3K) and serine/threonine kinase (Akt) have been reported to function downstream of daf-2 in C. elegans as well (Paradis et al., 1999; Paradis and Ruvkun, 1998). Akt kinases phosphorylate the DAF-16/FOXO transcription factor and negatively regulate the transcriptional activity of DAF-16. Insulin/IGF signaling is important for the regulation of development and behaviors in response to environmental factors (Gems et al., 1998; Tomioka et al., 2006). In addition, the presence of certain strains of bacteria in the diet has been reported to increase the body size of $C$. elegans. Animals fed $E$. coli HB101 were reported to grow larger than those fed a standard E. coli OP50 diet (So et al., 2011). The effect of the HB101 diet was reduced in daf-2 mutants, suggesting that DAF-2 insulin/IGF receptors are involved in the regulation of body size through food quality.

Signals from the germ line have also been reported to regulate lifespan and body size (Patel et al., 2002). Germ line ablation leads to longer lifespans and this lifespan extension is suppressed by daf-16 mutations. Ablation of germ line cells also causes animals to grow larger. Unlike the regulation of longevity, the effect of germ line signaling on body size is independent of DAF-16. As body size regulation by germ line signaling has also been shown to be 
independent of the TGF- $\beta$ ligand, DBL-1, the molecular mechanism of this regulation is currently unknown.

The target of rapamycin (TOR) pathway affects developmental regulation and acts downstream of insulin signaling (Scott et al., 1998; Sekulić et al., 2000). The serine-threonine kinase TOR functions in two distinct complexes, TORC1 and TORC2. The TORC1 pathway regulates cell growth through the initiation factor 4E-BP, which is associated with translation factors and ribosomal S6 kinase (S6K) in animals (Gingras et al., 2001). Mutations in the Drosophila TOR homolog, dTOR, cause a reduction in body size because of a reduction in cell size and number (Zhang et al., 2000). The dS6K mutants are also smaller than wild-type Drosophila (Montagne et al., 1999). TORC2 also regulates body size in Drosophila and $C$. elegans (Hietakangas and Cohen, 2007; Lee and Chung, 2007). Rictor, which encodes one of the TORC2 components, positively regulates body size in $C$. elegans, and Rictor mutants (rict-1) are smaller than wild-type animals (Jones et al., 2009). Furthermore, Rictor functions independent of the TGF- $\beta$ pathway or akt-1 and daf-16, which are components of the insulin-like signaling pathway, while sgk-1, the homolog of the serum-and glucocorticoid-induced kinase, acts downstream of TORC2.

Mutants for sma-5, which encodes a MAP kinase BMK1/ERK5, are smaller than wild-type C. elegans (Watanabe et al., 2005). The MAPK pathway also affects body size independent of the TGF- $\beta$ pathway. Double mutants, with defects in both MAPK and TGF- $\beta$ pathways, are smaller than single mutants (Watanabe et al., 2007).

The Hippo pathway was first identified in Drosophila, and its role in the regulation of development is well established (Justice et al., 1995; Xu et al., 1995; Yu et al., 2015). The components of this pathway are evolutionarily conserved and involved in cell proliferation, thus controlling organ and body sizes. Some genes encoding homologs of the Hippo pathway components have been identified in $C$. elegans. RNAi knockdown of the warts homolog, wts-1, results in small body size in C. elegans (Cai et al., 2009). However, the function of wts-1 in C. elegans may be different from that in Drosophila, which negatively regulates overgrowth. Analyses of epistasis showed that wts-1 regulates body size independent of the TGF- $\beta$ pathway.

\section{Body size is regulated by the quality and quantity of food}

Body size is also affected by the quality of diet. For example, animals fed Comamonas DA1877 developed faster and grew larger than those fed E. coli OP50 (MacNeil et al., 2013). This was because of vitamin B12, which is produced by Comamonas DA1877, but not by E. coli OP50 (Watson et al., 2014). As mentioned in the previous section, the E. coliHB101 diet has also been reported to cause an increase in body size (So et al., 2011), and this regulation requires insulin/IGF signaling. In addition, quantity of diet also affects body size. C. elegans swallow bacteria by rhythmically moving their pharynx (pharyngeal pumping). The rate of pharyngeal pumping determines the amount of food taken in. Mutants with defective pharyngeal pumping have been shown to take in food less efficiently, and to be smaller, than wild-type animals (Mörck and Pilon, 2006; So et al., 2011). For example, eat-2 mutants, which have defects in the mechanism for receiving signals from the pharyngeal neurons, are smaller than wild-type animals. The mutants for pha-2 and pha-3, which are required for normal pharyngeal development, also exhibit smaller body size than wild-type animals. Similarly, animals grown in conditions with food scarcity are smaller than those grown with sufficient food (Lenaerts et al., 2008). These results indicate that reduced food intake results in smaller body size. Moreover, decreased food intake has a transgenerational effect. Animals that experience starvation during the L1 larval stage produce progeny with shorter body lengths (Jobson et al., 2015), suggesting that severe starvation causes decreased body length in progeny through epigenetic regulation.

\section{Environmental factors regulate body size}

Environmental stimuli can also regulate body size. In general, ectotherms grown at lower temperatures achieve larger sizes, and this phenomenon is called the temperature-size rule. Standard N2 wild-type animals used in most laboratory experiments seems to comply with this rule and grow larger when cultured at $12{ }^{\circ} \mathrm{C}$ than at $24{ }^{\circ} \mathrm{C}$ (Kammenga et al., 2007). However, body size alteration based on temperature is not observed in a wild isolate, CB4856. This is due to a single nucleotide polymorphism in tra-3, which encodes a calpain-like protease. Further, CB4856 animals are smaller than N2 animals, even when grown at standard temperatures, due to a variation in $n p r-1$, which encodes a $G$ protein-coupled receptor related to neuropeptide $Y$ receptors (Andersen et al., 2014).

C. elegans, when raised in isolation, exhibit decreased developmental rates and smaller body sizes compared to animals raised in groups (Rose et al., 2005). Isolated animals also exhibit decreased responses to mechanical stimulation. However, mechanosensory stimulation during development reversed the effect of isolation on body size and mechanosensory response. Furthermore, isolation had no effect on the body size of mutants for $m e c-4$, which is essential for the functioning of touch-sensing neurons. These results demonstrate that mechanosensory neurons regulate the body size based on the level of sensory stimulation received during development.

Calcineurin, a calcium- and calmodulin-dependent serine/ threonine protein phosphatase, is also involved in body size regulation. Mutants for tax 6 and $c n b-1$, which encode the calcineurin subunits $A$ and $B$, respectively, are smaller than wild-type animals (Bandyopadhyay et al., 2002; Kuhara et al., 2002). Although the effect of tax- 6 mutants on body size could be partially suppressed by the expression of TAX- 6 in body wall muscles, it is fully suppressed only by pan-neuronal expression of the tax- 6 cDNA. These results suggest that calcium signaling is induced in neurons by environmental stimuli, and that it regulates body size via the calcineurin pathway.

Ciliated sensory neurons can perceive environmental stimuli such as odor, salt, temperature, and $\mathrm{pH}$. che-2 gene, which encodes a WD protein, is required for cilia formation and for perception of various stimuli (Fujiwara et al., 1999). che-2 mutants are smaller than wild-type animals, suggesting that perception of environmental stimuli is important for the regulation of body size (Fujiwara et al., 2002). However, mutants for egl-4, which encodes a cGMP-dependent protein kinase and is expressed in most neurons, are larger than wild-type animals. The egl-4 mutation suppresses the reduction in body size of che-2 mutants; the effect of egl-4 is mediated by its function in the ciliated sensory neurons. The egl-4 gene regulates body size by negatively regu- 
Fig. 2. Images of wild-type and cat-2 mutant animals. Images were taken from the N2 wild-type animals and the dopamine-defective mutants (cat-2mutants). The cat-2(e1112) mutant has an early nonsense mutation. The cat-2 mutants are larger than wild-type animals, suggesting that dopamine negatively regulates body size. The bar indicates $200 \mu \mathrm{m}$.

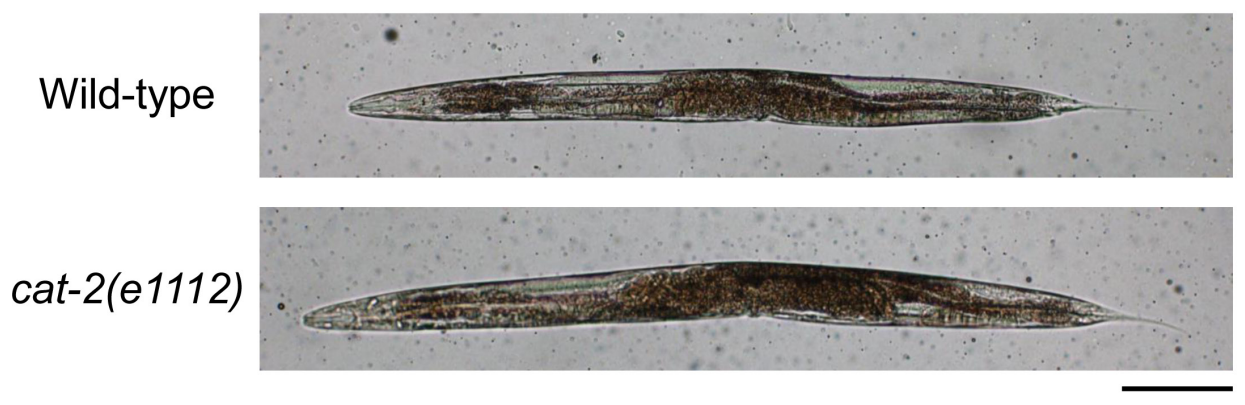

lating TGF- $\beta$ signaling. EGL-4 decreases DBL-1 signals from the neurons, which acts on the SMA-6 receptor of the hypodermal cells. Together, these results demonstrate that the nervous system plays a key role in the regulation of body size by environmental stimuli. However, the specific neurotransmitter responsible for the regulation of body size is still unclear. Recently, we found that a monoamine neurotransmitter, dopamine, regulates body size in C. elegans (Nagashima et al., 2016).

\section{Dopamine regulates body size}

In mammals, amine neurotransmitters such as dopamine and noradrenaline play critical roles in the regulation of behavior and metabolism. In C. elegans, dopamine is involved in sensing food and in food-dependent behavioral changes (Hills et al., 2004; Sawin et al., 2000). There are eight dopaminergic neurons in hermaphrodite $C$. elegans and they are all morphologically mechanosensory neurons (Sulston et al., 1975). It has been suggested that these neurons directly sense bacteria by touch and release dopamine in the presence of suitable food. The released dopamine causes multiple behavioral changes, including reduced locomotion and increased backward movement (Kindt et al., 2007; Sanyal et al., 2004). Five dopamine receptors have been identified in $C$. elegans: a D1-like receptor, DOP-1 (Sanyal et al., 2004; Suo et al., 2002); D2-like receptors, DOP-2 and DOP-3 (Chase et al., 2004; Sugiura et al., 2005; Suo et al., 2003); an invertebrate-specific receptor, DOP-4 (Sugiura et al., 2005); and a dopamine-gated chloride channel, LGC-53 (Ringstad et al., 2009). Octopamine is another monoamine neurotransmitter, considered the biological equivalent of noradrenaline (Roeder, 1999). In C. elegans, octopamine signaling is activated in the absence of food (Suo et al., 2006), and dopamine suppresses this octopamine signaling (Kimura et al., 2010; Suo et al., 2009). This regulation prevents the activation of octopamine signaling in the presence of food, as dopamine signaling is active. There are three octopamine receptors identified to date: Gq-coupled receptors, SER-3 and SER-6, and a Gi-coupled receptor, OCTR-1 (Suo et al., 2006; Wragg et al., 2007; Yoshida et al., 2014). Although many of the roles that these neurotransmitters and their receptors play in the regulation of behavior and metabolism of $C$. elegans have been elucidated, the effects of dopamine on development are still unclear.

It was recently found that dopamine negatively regulates body size in C. elegans (Nagashima et al., 2016). Mutants for cat-2 gene, which encodes tyrosine hydroxylase, a rate-limiting enzyme for dopamine synthesis, have a decreased level of dopamine and exhibits greater body length and width, compared to wild-type animals (Fig. 2). This increased body length of cat-2 mutants was suppressed by the introduction of the wild-type cat-2 gene or exogenous dopamine, suggesting that endogenous dopamine suppresses body size. Interestingly, the regulation of body size by dopamine is limited to hermaphrodites. The body length of male cat-2 mutants was not significantly different from that of wild-type males. The D2-like dopamine receptor, DOP-3, is likely the receptor through which dopamine functions for body size regulation. Among the five dopamine receptor mutants tested, dop-3 mutants were longest, with similar length as cat-2 mutants. In contrast, dop-4 mutants were shorter than wild-type animals. The body length of dop-3;dop-4 double mutants was not different from that of dop-3 single mutants, suggesting that $d o p-3$ plays a major role in body size regulation by dopamine. These results demonstrate that dopamine negatively regulates body size and that DOP-3 receptors are critical for body size regulation by dopamine.

\section{Factors downstream of dopamine}

Genetic analyses have revealed that octopamine signaling acts downstream of dopamine for body size regulation (Nagashima et al., 2016). tbh-1 encodes tyramine $\beta$-hydroxylase, which is required for octopamine synthesis, and therefore, $t b h-1$ mutants lack octopamine (Alkema et al., 2005). The body length of cat-2;tbh-1 double mutants was not different from that of wild-type animals (or tbh-1 single mutants), indicating that the increased body length of cat-2 mutants was suppressed by tbh-1. This result suggests that octopamine signaling is activated in cat-2 mutants, and that the activated octopamine signaling leads to increased body size; however, this effect is absent in cat-2;tbh-1 double mutants, in which octopamine signaling is inactivated. Furthermore, the body length enlargement of cat-2 mutants was at least partially suppressed in the background of octopamine receptor mutants, ser-3 and ser-6. These results suggest that the octopamine-SER-3/6 signaling pathway functions downstream of dopamine to regulate the body size in $C$. elegans.

As reduced food intake results in reduced body size, it is possible that dopamine affects food intake to regulate the body size. The pharyngeal pumping rate of cat-2 mutants was not significantly different from that of wild-type animals, suggesting that the quantity of food is not related to body size regulation by dopamine. Food quality also does not appear to play a role in the dopamine-induced regulation of body size, because even when cat-2 mutants were raised on the DA1877 or HB101 diets, they were larger than wild-type animals. However, body size regulation by dopamine did depend on the insulin/IGF receptor, DAF-2, which is also essential for the diet-dependent increase in body size. Body length of cat-2;daf-2 double mutants was not significantly different from 
that of the daf-2 single mutants; increased body length of cat-2 mutants was suppressed in the background of the daf-2 mutation. This result suggests that the insulin/IGF signal acts downstream of dopamine for body size regulation.

\section{The relationship between dopamine and the TGF- $\beta$ pathway}

The relationship between body size regulation by dopamine and the TGF- $\beta$ pathway has been studied (Nagashima et al., 2016). Both che-2(sensory functions) and egl-4(cGMP-dependent protein kinase) act upstream of the TGF- $\beta$ signals (Fujiwara et al., 2002). cat-2; che-2double mutants were longer than che-2single mutants, suggesting that dopamine regulates body size independent of che-2. However, the body length of cat-2;egl-4 double mutants was not significantly different from that of the egl-4 single mutants, suggesting that dopamine depends on egl-4 for the regulation of body size. The egl-4 gene is expressed in many neurons and supports various biological functions (Daniels et al., 2000; Hao et al., 2011). Therefore, it is possible that dopamine requires egl-4 in neurons (other than the sensory neurons), in which egl-4 functions downstream of che-2 for body size regulation.

The relationship between dopamine and the TGF- $\beta$ ligand, DBL1, was examined (Nagashima et al., 2016). Three different alleles of the $d b /-1$ mutants and two different alleles of the cat-2 mutants were investigated. The increase in body length of cat-2 mutants was not suppressed in any of the allele combinations, except one. This result supports the idea that dopamine regulates body size independent of the TGF- $\beta$ ligand. sma- 2 and sma-3 encode SMAD transcription factors that act downstream of sma-6, which encodes a subunit of the DBL-1 receptor. Dopamine appears to act independent of the SMAD transcription factors, because double mutants for cat-2 and sma-2 or sma-3 were longer than the sma-2 or sma-3 single mutants, respectively, although the difference was very small. These results also support the possibility that dopamine regulates body size independent of the TGF- $\beta$ pathway. However, cat-2;sma-6 double mutants were extremely sick, and the relationship between cat-2 and sma- 6 is still unknown. Thus, the apparent suppression of cat-2 by $d b /-1$ in one allele combination suggests a possibility that the regulation of body size by dopamine partially depends on the TGF- $\beta$ pathway.

\section{Roles of dopamine in body size regulation}

Regulation of body size by dopamine has been reported in several organisms. In mice, D2 dopamine receptors regulate body size by regulating GH secretion (Noaín et al., 2013). In humans, hypersecretion of $\mathrm{GH}$ and elevated levels of IGF-1 cause acromegaly, a disease associated with increased body size. Patients with acromegaly are treated with dopamine agonists such as cabergoline, which suppresses GH secretion (Abs et al., 1998). Moreover, an association between stature and polymorphism in the promoter region of the human D2 dopamine receptor gene has been reported; lower transcriptional activity of the receptor results in greater stature (Arinami etal., 1999). In mammals, dopamine signaling is also affected by food in the context of body size regulation. It has been reported that offspring of mice fed high-fat diets gain weight through epigenetic regulation. In the offspring, the expression of dopamine reuptake transporters was increased, whereas that of D1 and D2 dopamine receptors was reduced (Vucetic et al., 2010). Taken together, these results suggest that dopamineinduced regulation of body size may be conserved across species.

The TGF- $\beta$ pathway regulates polyploidization of hypodermal nuclei and this could affect body size by regulating the size of the hypodermal cells (Morita et al., 2002). The TGF- $\beta$ ligand, $\mathrm{DBL}-1$, is produced in the neurons and transmits the signal to

\section{Regulation by the nervous system}

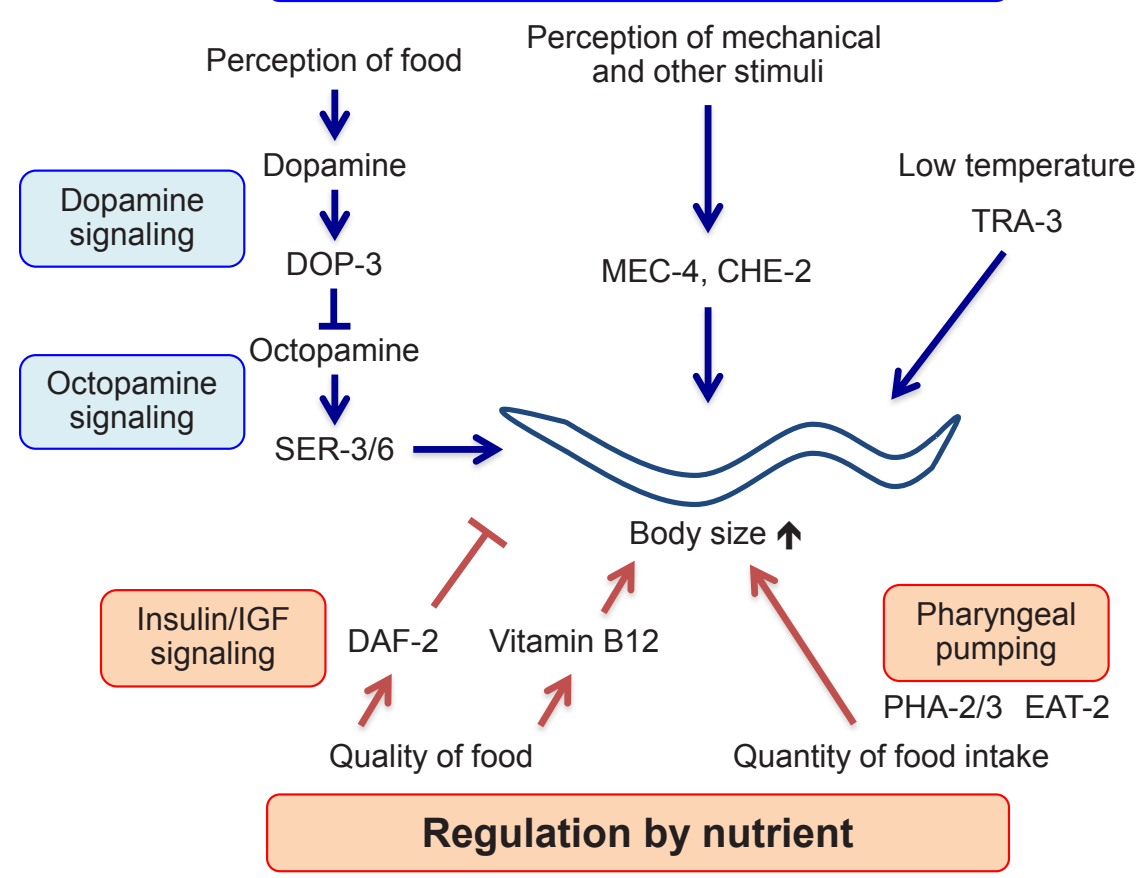

Fig. 3. A model for the regulation of body size by environmental factors in Caenorhabditis elegans. Several stimuli from the ambient environment affect body size. These stimuli are perceived by sensory neurons and the resultant signals from the nervous system influences body size (blue arrows). Dopamine, which is thought to be released upon tactile perception of food, negatively regulates body size through the DOP-3 dopamine receptor. Dopamine signaling negatively regulates octopamine signaling, which signals through SER-3 and SER-6 octopamine receptors. The observation that body size is regulated by dopamine, which has a role in the perception of food, suggests that not just ingestion, but the perception of food also regulates body size via the nervous system. The perception of mechanical and other stimuli by the amphid sensory neurons affects body size through MEC-4 and CHE-2, respectively. Low temperatures cause larger body sizes in animals, and this regulation requires TRA-3, a calpain-like protease. Both quality and quantity of food intake affect body size (red arrows). Animals fed the bacterial strain HB101 grow larger than those fed OP50, and this regulation is mediated by the insulin/IGF receptor, DAF-2. Bacterial strains that contain vitamin B12, such as Comamonas DA1877, also accelerate the animal development. PHA-2/3 and EAT-2 are required for the normal development and function, respectively, of the pharynx. Food intake is reduced in pha- $2 / 3$ and eat-2 mutants, which reduces the size of these animals. 
the hypodermal cells. The SMA- 6 receptor, which is expressed in the hypodermal cells, regulates gene expression through the transcription factors, SMA-2 and SMA-3, which in turn regulate the polyploidization. If dopamine does indeed act independent of DBL-1, it may be using different molecules to transmit the signal from neurons to other tissues. It is unlikely that dopamine itself, or octopamine, signals the hypodermis because there have been no reports on the expression of dopamine receptors or octopamine receptors in the hypodermis. As dopamine requires the insulin/ IGF receptor, DAF-2, for the regulation of body size, it is possible that insulin/IGF ligands transmit the signal from the neurons to the non-neuronal cells.

Food is an important factor in the regulation of body size (Fig. 3). Both quantity and quality of food have been shown to exert a significant effect on the body size of $C$. elegans. Dopamine does not appear to play a role in regulation of food intake since cat-2 mutants exhibited normal pharyngeal pumping. Dopamine is also not involved in the alteration of body size due to different bacterial strains in the diet. However, dopamine has been reported to be involved in food sensing in C. elegans (Hills et al., 2004; Sawin et al., 2000). The dopaminergic neurons in $C$. elegans are mechanosensory (Sulston et al., 1975). The sensory endings of these neurons are embedded in the cuticle and can directly sense food bacteria by touch (Sawin et al., 2000). It has been proposed that the tactile perception of food bacteria in the environment induces dopamine release from these neurons, even without ingestion of the bacteria. The observation that dopamine negatively regulates body size suggests that perception of food regulates body size and so, food affects body size not only as a nutrient, but also through its sensory perception.

\section{Acknowledgements}

This work was supported by JSPS KAKENHI Grant Numbers 26870126 and $16 K 07063$ (to S. S.), an Intramural Research Grant (26-8) for Neurological and Psychiatric Disorders of NCNP, a research grant for Comprehensive Research on Disability Health and Welfare from the Ministry of Health, Labour and Welfare (MHLW; H26-Sinkeikinn-ippan-004), and a Grant-in-Aid from the MHLW of Japan (to S. I.).

\section{References}

ABS R, VERHELST J, MAITER D, VAN ACKER K, NOBELS F, COOLENS JL, MAHLER C, BECKERS a (1998). Cabergoline in the treatment of acromegaly: a study in 64 patients. J Clin Endocrinol Metab 83: 374-378.

ALKEMA MJ, HUNTER-ENSOR M, RINGSTAD N, HORVITZ HR (2005). Tyramine Functions independently of octopamine in the Caenorhabditis elegans nervous system. Neuron 46: 247-260.

ANDERSEN EC, BLOOM JS, GERKE JP, KRUGLYAK L (2014). A Variant in the Neuropeptide Receptor npr-1 is a Major Determinant of Caenorhabditis elegans Growth and Physiology. PLoS Genet 10.

ARINAMI T, IIJIMA Y, ISHIGURO H, OHTSUKI T (1999). Supportive evidence for contribution of the dopamine $\mathrm{D} 2$ receptor gene to heritability of stature : linkage and association studies. Ann. Hum. Genet. 63: 147-151.

BAIRD SE, ELLAZAR SA (1999). TGF $\beta$-like signaling and spicule development in Caenorhabditis elegans. Dev Biol 212: 93-100.

BANDYOPADHYAY J, LEE J, LEE J, LEE JI, YU JR, JEE C, CHO JH, JUNG S, LEE MH, ZANNONI S, SINGSON A, KIM DH, KOO HS, AHNN J (2002). Calcineurin, a calcium/calmodulin-dependent protein phosphatase, is involved in movement, fertility, egg laying, and growth in Caenorhabditis elegans. Mol Biol Cell13:3281-3293.

BLUTKE A, SCHNEIDER MR, RENNER-MÜLLER I, HERBACH N, WANKE R, WOLF E (2014). Genetic dissection of IGF1-dependent and -independent effects of permanent GH excess on postnatal growth and organ pathology of mice. Mol
Cell Endocrinol 394: 88-98.

BÖHNIR, RIESGO-ESCOVARJ, OLDHAMS, BROGIOLOW, STOCKERH,ANDRUSS BF, BECKINGHAM K, HAFEN E (1999). Autonomous Control of Cell and Organ Size by CHICO, a Drosophila Homolog of Vertebrate IRS1--4. Cell 97: 865-875.

BROGIOLO W, STOCKER H, IKEYA T, RINTELEN F, FERNANDEZ R, HAFEN E (2001). An evolutionarily conserved function of the Drosophila insulin receptor and insulin-like peptides in growth control. Curr Biol 11: 213-221.

CAI Q, WANG W, GAO Y, YANG Y, ZHU Z, FAN Q (2009). Ce-wts-1 plays important roles in Caenorhabditis elegans development. FEBS Lett 583: 3158-3164.

CHASE DL, PEPPER JS, KOELLE MR (2004). Mechanism of extrasynaptic dopamine signaling in Caenorhabditis elegans. Nat Neurosci 7: 1096-1103.

DANIELS S a., AILION M, THOMAS JH, SENGUPTA P (2000). egl-4 Acts through a transforming growth factor- $\beta / S M A D$ pathway in Caenorhabditis elegans to regulate multiple neuronal circuits in response to sensory cues. Genetics 156: 123-141.

DYERAH, VAHDATPOURC, SANFELIUA, TROPEAD (2016). The role of Insulin-Like Growth Factor 1 (IGF-1) in brain development, maturation and neuroplasticity. Neuroscience 325: 89-99.

ESTEVEZ M, ATTISANO L, WRANA JL, ALBERT PS, MASSAGUÉ J, RIDDLE DL (1993). The daf-4 gene encodes a bone morphogenetic protein receptor controlling C. elegans dauer larva development. Nature 365: 644-649.

FRENCH V, FEAST M, PARTRIDGE L (1998). Body size and cell size in Drosophila: The developmental response to temperature. J Insect Physiol 44: 1081-1089.

FUJIWARA M, ISHIHARA T, KATSURA I (1999). A novel WD40 protein, CHE-2, acts cell-autonomously in the formation of $C$. elegans sensory cilia. Development 126: $4839-4848$.

FUJIWARAM, SENGUPTAP, MCINTIRE SL (2002). Regulation of body size and behavioral state of $C$. elegans by sensory perception and the egl-4cGMP-dependent protein kinase. Neuron 36: 1091-1102.

GEMS D, SUTTON AJ, SUNDERMEYER ML, ALBERT PS, KING K V., EDGLEY ML, LARSEN PL, RIDDLE DL (1998). Two pleiotropic classes of daf-2 mutation affect larval arrest, adult behavior, reproduction and longevity in Caenorhabditis elegans. Genetics 150: 129-155.

GINGRASA, RAUGHTB, SONENBERG N (2001). Regulation of translation initiation by FRAP / mTOR. Genes Dev 15: 807-826.

HAO Y, XU N, BOXAC, SCHAEFER L, KANNAN K, ZHANG Y, FLORENS L, SEIDEL C, WASHBURN MP, WIEGRAEBE W, MAK HY (2011). Nuclear cGMP-dependent kinase regulates gene expression via activity-dependent recruitment of a conserved histone deacetylase complex. PLoS Genet 7: e1002065.

HIETAKANGAS V, COHEN SM (2007). Re-evaluating AKT regulation: role of TOR complex 2 in tissue growth. Genes Dev. 21: 632-637.

HILLS T, BROCKIE PJ, MARICQ A V (2004). Dopamine and glutamate control arearestricted search behavior in Caenorhabditis elegans. J Neurosci24: 1217-1225.

JOBSON MA, JORDAN JM, SANDROF MA, HIBSHMAN JD, LENNOX AL, BAUGH LR (2015). Transgenerational effects of early life starvation on growth, reproduction, and stress resistance in Caenorhabditis elegans. Genetics 201: 201-212.

JONES KT, GREER ER, PEARCE D, ASHRAFI K (2009). Rictor/TORC2 regulates Caenorhabditis elegans fat storage, body size, and development through sgk-1. PLOS Biol 7: 0604-0615.

JUSTICE RW, ZILIAN O, WOODS DF, NOLL M, BRYANT PJ (1995). The Drosophila tumor suppressor gene warts encodes a homolog of human myotonic dystrophy kinase and is required for the control of cell shape and proliferation. Genes Dev 9: 534-546.

KAMMENGA JE, DOROSZUK A, RIKSEN JAG, HAZENDONK E, SPIRIDON L, PETRESCU AJ, TIJSTERMAN M, PLASTERK RHA, BAKKER J (2007). A Caenorhabditis elegans wild type defies the temperature-size rule owing to a single nucleotide polymorphism in tra-3. PLoS Genet 3: 0358-0366.

KENNINGTON WJ, KILLEEN JR, GOLDSTEIN DB, PARTRIDGE L (2003). Rapid laboratory evolution of adult wing area in Drosophila melanogaster in response to humidity. Evolution (N Y) 57: 932-936.

KIMURAKD, FUJITAK, KATSURAI (2010). Enhancement of odor avoidance regulated by dopamine signaling in Caenorhabditis elegans. J Neurosci 30: 16365-16375.

KINDT KS, QUAST KB, GILES AC, DE S, HENDREY D, NICASTRO I, RANKIN CH, SCHAFER WR (2007). Dopamine mediates context-dependent modulation of sensory plasticity in C. elegans. Neuron 55: 662-676.

KRISHNA S, MADUZIA L, RW P (1999). Specificity of TGF $\beta$ signaling is cnferred by 
distinct type I receptors and their associated SMAD proteins in Caenorhabditis elegans. Development 126: 251-260.

KUHARAA, INADAH, KATSURAI, MORI I (2002). Negative regulation and gain control of sensory neurons by the $C$. elegans calcineurin TAX-6. Neuron 33: 751-763.

LAYALLE S, ARQUIER N, LÉOPOLD P (2008). The TOR pathway couples nutrition and developmental timing in Drosophila. Dev Cell 15: 568-577.

LEE G, CHUNG J (2007). Discrete functions of rictor and raptor in cell growth regulation in Drosophila. Biochem Biophys Res Commun 357: 1154-1159.

LENAERTS I, WALKER G a, VAN HOOREBEKE L, GEMS D, VANFLETEREN JR (2008). Dietary restriction of Caenorhabditis elegans by axenic culture reflects nutritional requirement for constituents provided by metabolically active microbes. $J$ Gerontol A Biol Sci Med Sci 63: 242-252.

LIANG J, LINTS R, FOEHR ML, TOKARZ R, YU L, EMMONS SW, LIU J, SAVAGEDUNN C (2003). The Caenorhabditis elegans schnurri homolog sma-9 mediates stage- and cell type-specific responses to DBL-1 BMP-related signaling. Development 130: 6453-6464.

LIN S, THOMAS TC, STORLIEN LH, HUANG XF (2000). Development of high fat dietinduced obesity and leptin resistance in C57BI/6J mice. Int J Obes 24: 639-646.

LUNDBERG E, KRISTRÖM B, JONSSON B, ALBERTSSON-WIKLAND K (2015). Growth hormone $(\mathrm{GH})$ dose-dependent IGF-I response relates to pubertal height gain. BMC Endocr Disord 15: 84.

MACNEIL LT, WATSON E, ARDA HE, ZHU LJ, WALHOUT AJM (2013). Diet-induced developmental acceleration independent of TOR and insulin in C. elegans. Cell 153: 240-252.

MADUZIALL, GUMIENNY TL, ZIMMERMAN CM, WANG H, SHETGIRI P, KRISHNA S, ROBERTS AF, PADGETT RW (2002). Ion-1 regulates Caenorhabditis elegans body size downstream of the $d b /$-1TGF $\beta$ signaling pathway. Dev Biol246:418-428.

MASSAGUÉ J (2012). TGF $\beta$ signalling in context. Nat Rev Mol Cell Biol 13: 616-630.

MASUYAMA H, HIRAMATSU Y (2012). Effects of a high-fat diet exposure in utero on the metabolic syndrome-like phenomenon in mouse offspring through epigenetic changes in adipocytokine gene expression. Endocrinology 153: 2823-2830.

DE MOED GH, DE JONG G, SCHARLOOW (1997). Environmental effects on body size variation in Drosophila melanogaster and its cellular basis. Genet Res 70: 35-43.

MONTAGNE J, STEWART MJ, STOCKER H, HAFEN E, KOZMA SC, THOMAS G (1999). Drosophila S6 kinase: a regulator of cell size. Science 285: 2126-2129.

MÖRCK C, PILON M (2006). C. elegans feeding defective mutants have shorter body lengths and increased autophagy. BMC Dev Biol 6: 39.

MORITA K, CHOW KL, UENO N (1999). Regulation of body length and male tail ray pattern formation of Caenorhabditis elegans by a member of TGF- $\beta$ family. Development 126: 1337-1347.

MORITAK, FLEMMINGAJ, SUGIHARAY, MOCHII M, SUZUKIY, YOSHIDAS, WOOD WB, KOHARA Y, LEROI AM, UENO N (2002). A Caenorhabditis elegans TGF- $\beta$, DBL-1, controls the expression of LON-1, a PR-related protein, that regulates polyploidization and body length. EMBO J 21: 1063-1073.

NAGASHIMAT, OAMIE, KUTSUNAN, ISHIURAS, SUOS(2016). Dopamine regulates body size in Caenorhabditis elegans. Dev Biol 412: 128-138.

NÄSSEL DR, LIU Y, LUO J (2015). Insulin/IGF signaling and its regulation in Drosophila. Gen Comp Endocrinol 221: 255-266.

NOAÍN D, PÉREZ-MILLÁN MI, BELLO EP, LUQUE GM, CASAS CORDERO R, GELMAN DM, PEPER M, TORNADU IG, LOW MJ, BECÚ-VILLALOBOS D, RUBINSTEIN M (2013). Central dopamine D2 receptors regulate growth-hormone-dependent body growth and pheromone signaling to conspecific males. $J$ Neurosci 33: 5834-5842.

PARADIS S, AILION M, TOKERA, THOMAS JH, RUVKUN G (1999). APDK1 homolog is necessary and sufficient to transduce AGE-1 PI3 kinase signals that regulate diapause in Caenorhabditis elegans. Genes Dev 13: 1438-1452.

PARADIS S, RUVKUN G (1998). Caenorhabditis elegans Akt/PKB transduces insulin receptor-like signals from age-1 $\mathrm{PI} 3$ kinase to the DAF-16 transcription factor. Genes Dev 12: 2488-2498.

PATEL MN, KNIGHT CG, KARAGEORGI C, LEROI AM (2002). Evolution of germline signals that regulate growth and aging in nematodes. Proc Natl Acad Sci USA 99: 769-774.

PATTERSON GI, PADGETTRW (2000). TGF $\beta$-related pathways: roles in Caenorhabditis elegans development. Trends Genet 16: 27-33.
RINGSTAD N, ABE N, HORVITZ HR (2009). Ligand-gated chloride channels are receptors for biogenic amines in C. elegans. Science 325: 96-100.

RITTER AD, SHEN Y, BASS JF, JEYARAJ S, DEPLANCKE B, MUKHOPADHYAY A, XU J, DRISCOLL M, TISSENBAUM HA, WALHOUT AJM (2013). Complex expression dynamics and robustness in $C$. elegans insulin networks. Genome Res 23: 954-965.

ROBERTSON F (1959). Studies in quantitative inheritance. XII. Cell size and number in relation to genetic and environmental variation of body size in Drosophila. Genetics: 869-896.

ROEDER T (1999). Octopamine in invertebrates. Prog Neurobiol 59: 533-561.

ROSE JK, SANGHA S, RAI S, NORMAN KR, RANKIN CH (2005). Decreased sensory stimulation reduces behavioral responding, retards development, and alters neuronal connectivity in Caenorhabditis elegans. J Neurosci 25: 7159-7168.

RUAL JF, CERON J, KORETH J, HAO T, NICOT AS, HIROZANE-KISHIKAWA T, VANDENHAUTE J, ORKIN SH, HILL DE, VAN DEN HEUVELS, VIDAL M (2004). Toward improving Caenorhabditis elegans phenome mapping with an ORFeomebased RNAi library. Genome Res 14: 2162-2168.

SANYAL S, WINTLE RF, KINDT KS, NUTTLEY WM, ARVAN R, FITZMAURICE P, BIGRASE, MERZDC, HEBERTTE, VANDER KOOYD, SCHAFERWR, CULOTTI JG, VANTOL HHM (2004). Dopamine modulates the plasticity of mechanosensory responses in Caenorhabditis elegans. EMBO J 23: 473-482.

SAWIN ER, RANGANATHAN R, HORVITZ HR (2000). C. elegans locomotory rate is modulated by the environment through a dopaminergic pathway and by experience through a serotonergic pathway. Neuron 26: 619-631.

SCOTT PH, BRUNN GJ, KOHN AD, ROTH RA, LAWRENCE JC (1998). Evidence of insulin-stimulated phosphorylation and activation of the mammalian target of rapamycin mediated by a protein kinase B signaling pathway. Proc Natl Acad Sci USA 95: 7772-7777.

SEKULIĆ A, HUDSON CC, HOMME JL, YIN P, OTTERNESS DM, KARNITZ LM, ABRAHAM RT (2000). Adirect linkage between the phosphoinositide 3-kinase-AKT signaling pathway and the mammalian target of rapamycin in mitogen-stimulated and transformed cells. Cancer Res 60: 3504-3513.

SERRAT MA, KING D, LOVEJOY CO (2008). Temperature regulates limb length in homeotherms by directly modulating cartilage growth. Proc Natl Acad Sci USA 105: 19348-19353.

SHIAO SH, HANSEN IA, ZHU J, SIEGLAFF DH, RAIKHEL AS (2008). Juvenile hormone connects larval nutrition with target of rapamycin signaling in the mosquito Aedes aegypti. J Insect Physiol 54: 231-239.

SHIMADA-NIWA Y, NIWA R (2014). Serotonergic neurons respond to nutrients and regulate the timing of steroid hormone biosynthesis in Drosophila. Nat Commun 5: 5778.

SOS, MIYAHARAK, OHSHIMAY (2011). Control of body size in C. elegans dependent on food and insulin/IGF-1 signal. Genes Cells 16: 639-651.

SUGIURA M, FUKE S, SUO S, SASAGAWA N, VAN TOL HHM, ISHIURA S (2005). Characterization of a novel D2-like dopamine receptor with a truncated splice variant and a D1-like dopamine receptor unique to invertebrates from Caenorhabditis elegans. J Neurochem 94: 1146-1157.

SULSTON J, DEW M, BRENNER S (1975). Dopaminergic neurons in the nematode Caenorhabditis elegans. J Comp Neurol 163: 215-226.

SUO S, CULOTTI JG, VAN TOL HHM (2009). Dopamine counteracts octopamine signalling in a neural circuit mediating food response in C. elegans. EMBO J 28: 2437-2448.

SUO S, KIMURA Y, VAN TOL HHM (2006). Starvation induces cAMP response element-binding protein-dependent gene expression through octopamine-Gq signaling in Caenorhabditis elegans. J Neurosci 26: 10082-10090.

SUO S, SASAGAWA N, ISHIURA S (2003). Cloning and characterization of a Caenorhabditis elegans D2-like dopamine receptor. J Neurochem 86: 869-878.

SUO S, SASAGAWA N, ISHIURA S (2002). Identification of a dopamine receptor from Caenorhabditis elegans. Neurosci Lett 319: 13-16.

SUZUKI Y, YANDELL MD, ROY PJ, KRISHNA S, SAVAGE-DUNN C, ROSS RM, PADGETT RW, WOOD WB (1999). A BMP homolog acts as a dose-dependent regulator of body size and male tail patterning in Caenorhabditis elegans. Development 126: 241-250.

TOMIOKA M, ADACHI T, SUZUKI H, KUNITOMO H, SCHAFER WR, IINO Y (2006). The Insulin/PI 3-Kinase Pathway Regulates Salt Chemotaxis Learning in Cae- 


\section{T. Nagashima et al.}

norhabditis elegans. Neuron 51: 613-625.

TRUMAN JW, RIDDIFORD LM (2007). The morphostatic actions of juvenile hormone. Insect Biochem Mol Biol 37: 761-770.

TUCK S (2014). The control of cell growth and body size in Caenorhabditis elegans. Exp Cell Res 321: 71-76.

VUCETIC Z, KIMMEL J, TOTOKI K, HOLLENBECK E, REYES TM (2010). Maternal high-fat diet alters methylation and gene expression of dopamine and opioidrelated genes. Endocrinology 151: 4756-4764.

WANG J, MOHLER W a, SAVAGE-DUNN C (2005). C-terminal mutants of $C$. elegans Smads reveal tissue-specific requirements for protein activation by TGF- $\beta$ signaling. Development 132: 3505-3513.

WATANABE N, ISHIHARA T, OHSHIMA Y (2007). Mutants carrying two sma mutations are super small in the nematode $C$. elegans. Genes Cells 12: 603-609.

WATANABE N, NAGAMATSU Y, GENGYO-ANDO K, MITANI S, OHSHIMAY (2005). Control of body size by SMA-5, a homolog of MAP kinase BMK1/ERK5, in $C$. elegans. Development 132: 3175-3184.

WATSON E, MACNEIL LT, RITTER AD, YILMAZ LS, ROSEBROCK AP, CAUDY AA, WALHOUT AJM (2014). Interspecies systems biology uncovers metabolites affecting $C$. elegans gene expression and life history traits. Cell 156: 759-770.
WRAGG RT, HAPIAK V, MILLER SB, HARRIS GP, GRAY J, KOMUNIECKI PR KOMUNIECKI RW (2007). Tyramine and octopamine independently inhibit serotonin-stimulated aversive behaviors in Caenorhabditis elegans through two novel amine receptors. J Neurosci 27: 13402-13412.

WU MY, HILL CS (2009). TGF- $\beta$ superfamily signaling in embryonic development and homeostasis. Dev Cell 16: 329-343.

XU T, WANG W, ZHANG S, STEWART R a, YU W (1995). Identifying tumor suppressors in genetic mosaics: the Drosophila lats gene encodes a putative protein kinase. Development 121: 1053-1063.

YOSHIDA M, OAMI E, WANG M, ISHIURA S, SUO S (2014). Nonredundant function of two highly homologous octopamine receptors in food-deprivation-mediated signaling in Caenorhabditis elegans. J Neurosci Res 92: 671-678.

YOSHIDA S, MORITA K, MOCHII M, UENO N (2001). Hypodermal expression of Caenorhabditis elegans TGF- $\beta$ type I receptor SMA-6 is essential for the growth and maintenance of body length. Dev Biol 240: 32-45.

YU FX, ZHAO B, GUAN KL (2015). Hippo Pathway in Organ Size Control, Tissue Homeostasis, and Cancer. Cell 163: 811-828.

ZHANG H, STALLOCK JP, NG JC, REINHARD C, NEUFELD TP (2000). Regulation of cellular growth by the Drosophila target of rapamycin dTOR. Genes Dev 14: 2712-2724. 


\section{Further Related Reading, published previously in the Int. J. Dev. Biol.}

Live imaging reveals spatial separation of parental chromatin until the four-cell stage in Caenorhabditis elegans embryos Jitka Bolková and Christian Lanctôt

Int. J. Dev. Biol. (2016) 60: 5-12

Expression of serotonergic system components during early Xenopus embryogenesis Denis A. Nikishin, Stanislav V. Kremnyov, Victoria V. Konduktorova and Yuri B. Shmukler Int. J. Dev. Biol. (2012) 56: 385-391

http://dx.doi.org/10.1387/ijdb.113475dn

Planarian regeneration: achievements and future directions after 20 years of research

Emili Saló, Josep F. Abril, Teresa Adell, Francesc Cebriá, Kay Eckelt, Enrique Fernández-Taboada, Mette Handberg-Thorsager, Marta Iglesias, M Dolores Molina and Gustavo Rodríguez-Esteban

Int. J. Dev. Biol. (2009) 53: 1317-1327

http://dx.doi.org/10.1387/ijdb.072414es

Signaling pathways during maintenance and definitive endoderm differentiation of embryonic stem cells Lina Sui, Luc Bouwens and Josué K. Mfopou

Int. J. Dev. Biol. (2013) 57: 1-12

http://dx.doi.org/10.1387/ijdb.120115ls

Hypoxia and neural stem cells: from invertebrates to brain cancer stem cells Ferdinando Mannello, Virginia Medda and Gaetana A Tonti

Int. J. Dev. Biol. (2011) 55: 569-581

http://dx.doi.org/10.1387/ijdb.103186fm

Differences in embryonic pattern formation between Caenorhabditis elegans and its close parthenogenetic relative Diploscapter coronatus

Vera Lahl, Jens Schulze and Einhard Schierenberg

Int. J. Dev. Biol. (2009) 53: 507-515

Genes required for the common miracle of fertilization in Caenorhabditis elegans Andrew Singson, Julie S. Hang and Jean M. Parry

Int. J. Dev. Biol. (2008) 52: 647-656

Differences in maternal supply and early development of closely related nematode species Magdalena Laugsch and Einhard Schierenberg

Int. J. Dev. Biol. (2004) 48: 655-662

http://dx.doi.org/10.1387/ijdb.031758ml

5 yr ISI Impact Factor $(2013)=2.879$
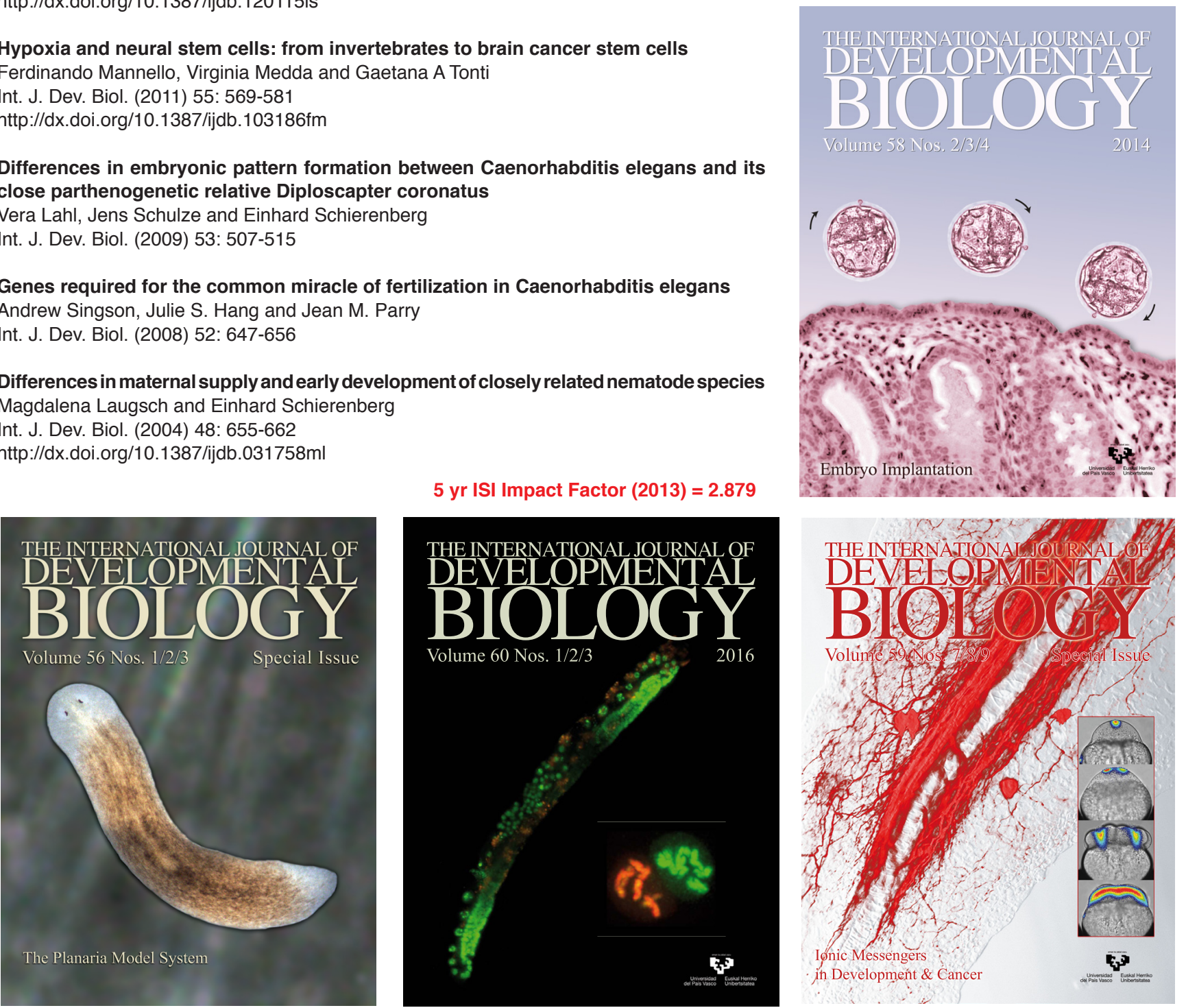